\title{
Lusotopie
}

Recherches politiques internationales sur les espaces issus de l'histoire et de la colonisation portugaises

$\mathrm{XIX}(1) \mid 2020$

Amílcar Cabral et l'idée de la révolution anticoloniale

\section{Amílcar Cabral, anthropologue de la tension}

Amílcar Cabral, antropólogo da tensão

Amilcar Cabral, Anthropologist of Tension

\section{Mamadou Kabirou Gano}

\section{(2) OpenEdition}

Journals

Édition électronique

URL : https://journals.openedition.org/lusotopie/4569

ISSN : 1768-3084

Éditeur

Idemec - UMR 7307

Édition imprimée

Date de publication : 4 août 2020

Pagination : $36-53$

ISSN : 1257-0273

Référence électronique

Mamadou Kabirou Gano, «Amílcar Cabral, anthropologue de la tension », Lusotopie [En ligne], XIX(1) I 2020, mis en ligne le 02 janvier 2022, consulté le 04 février 2022. URL : http://

journals.openedition.org/lusotopie/4569

Ce document a été généré automatiquement le 4 février 2022

Lusotopie 


\title{
Amílcar Cabral, anthropologue de la tension
}

\author{
Amílcar Cabral, antropólogo da tensão \\ Amilcar Cabral, Anthropologist of Tension
}

Mamadou Kabirou Gano

\section{Introduction}

1 La polarisation de la topologie du monde colonial entre oppression, désir de survie et aspiration au progrès institue dans l'univers colonial un rapport de forces éprouvant entre les protagonistes. En effet, la dialectique oppression-résistance somme individuellement tous les sujets de se dépasser pour s'en sortir. Dans l'ordre colonial, chacun est appelé d'une manière ou d'une autre à opérer des choix au milieu d'infinis possibles, et choisir un possible plutôt qu'un autre génère cette angoisse de la liberté que nous nommons ici tension. Son contenu intentionnel ou représentationnel traduit, de ce point de vue, la caractéristique mentale rendant possible une orientation, une direction dont celle de l'autre comme prochain. Comment s'effectue chez Cabral le procès de rationalisation de la réalité ? Quelle grille d'analyse permet de comprendre l'ordre colonial ? Comment saisir l'humanisme cabralien? Dans le propos qui suit, nous examinerons d'abord les fondements théoriques de sa démarche; ensuite nous évaluerons d'une part le rôle de la violence et de la culture dans l'ordre colonial dont le vœu constitutif avoué consiste à expérimenter une division de l'homme par l'aliénation et par la ségrégation raciale, et d'autre part la mutation anthropologique qui s'opère dans le processus de libération; enfin, nous esquisserons les prémisses de ce "nouvel humanisme", c'est-à-dire, la tentative de reconquête d'une humanité niée par les théories et les pratiques du racisme colonial. Cette reconquête s'accomplit par le dépassement de soi, par le biais de la lutte de libération et de la construction d'un nouvel ordre social et économique. 


\section{Partir des réalités}

\subsection{Des efforts de rationalisation du réel}

2 Cabral a instauré une certaine réflexivité dans son rapport au terrain politique et, du coup, il a développé une approche spécifique sous la modalité d'une attitude de distanciation vis-à-vis de l'objet d'étude, une sorte de "regard éloigné", pour reprendre le titre évocateur d'un ouvrage de Claude Lévi-Strauss (Lévi-Strauss 1983). En effet, nous retrouvons ce recul critique dans le travail de terrain, notamment dans l'enquête participante (Andrade 1980:12) menée en Guinée "portugaise" dans les années cinquante ayant permis d'appréhender les réalités sociales, culturelles et techniques de son pays ${ }^{1}$. À cette période, il avait procédé à un vaste recensement des productions agricoles qui lui avait permis, d'une part, d'acquérir une compréhension approfondie des populations, de leurs cultures, des mécanismes de l'aliénation et des formes de résistance à la domination; et d'autre part, d'établir un contact quotidien avec les populations préfigurant et préparant la mobilisation. En d'autres termes, avant d'engager l'action de mobilisation politique et la lutte armée, Cabral examine concrètement les structures sociales, en se donnant les moyens d'une lecture rigoureuse de la réalité sociale. L'analyse des structures sociales, précisément celles des différents groupes ethniques, aide à saisir le mécanisme de leur fonctionnement et leur rapport au pouvoir colonial afin d'agir sur elles. Cette théorisation nécessaire des rapports sociaux à l'intérieur des groupes culturels en relation avec le fait de la domination éclaire le mécanisme de l'aliénation, les ressorts psychologiques, éthiques et politiques de la résistance. Par ce biais, il saisit le rôle joué par la culture dans le processus de libération.

3 Le travail politique permanent, et toujours recommencé, part de ce fond en repérant son potentiel de changement mais aussi ses facteurs de résistance au changement. D'où l'effort théorique fourni pour examiner des objets conceptuels a priori non directement impliqués dans la guerre, mais pourtant essentiels à sa bonne conduite. Comme agitateur politique et stratège militaire, ou comme architecte de la construction nationale, "l'ingénieur" se fait, à chaque instant, anthropologue puisque toute la démarche a, en point de mire, l'homme comme moyen et fin ultime de l'engagement politique et militaire. Au cœur de cette pensée et de sa pratique politique prévaut une profonde sensibilité à l'expérience concrète des différents groupes sociaux et ethniques, une conscience de l'importance de la construction d'une stratégie politique et organisationnelle basée sur une connaissance des structures de la société et des expériences des différents groupes. Tout comme Kwame Nkrumah, Cabral a perçu la nature dialectique de la réalité: "le consciencisme pose le principe dialectique universel selon lequel toute réalité est un 'faisceau de forces en tension' et insiste sur la portée socio-politique de ce principe, sur la nature aussi bien des forces en tension que de cette tension elle-même". "De même que, tel l'arc d'Héraclite, l'immobilité apparente de la matière recouvre en réalité la tension d'un faisceau de forces, de même, dans un pays colonisé, une opposition de forces réactionnaires et révolutionnaires peut donner l'impression d'une sujétion définitive et acceptée" (Nkrumah ${ }^{2} 1964$ : 149-150). Toute société recèle un antagonisme de forces exprimant la vitalité du corps social. Ce constat amène Cabral à un examen minutieux des relations, des hiérarchies qui traversent la société et les communautés qui constituent le terrain politique et militaire de la lutte. Le trait caractéristique de la démarche fut une sorte d'empirisme attentif à 
la spécificité historique des formations sociales, des relations et des conditions d'existence. Par la description des modes de vie et par les relevés statistiques, il saisit les expériences quotidiennes, les traditions, les cultures, les techniques; d'où l'attention particulière accordée aux conditions de vie transcendant les divisions et forgeant les alliances entre les catégories sociales.

Le travail politique repère le potentiel de changement et les facteurs de résistance au changement, tout en élaborant une stratégie de développement de la lutte prenant en compte nécessairement la complexité des réalités analysées. Cette posture vise à parvenir à une connaissance intime de la carte ethnographique et économique du pays, celle aussi d'une lutte présupposant nécessairement la connaissance de des peuples, la compréhension de leurs croyances, de leurs valeurs, de leur organisation socioéconomique constamment rudoyées par le fait colonial et obligées, pour survivre, d'emprunter les sentiers de la clandestinité.

\subsection{De l'essence totalitaire de la violence coloniale}

5 La colonie pénitentiaire de Franz Kafka n'a pas toujours été une fiction, elle a eu une incarnation historique que le colonialisme, dans son apogée impérialiste, a pu traduire dans les faits à l'échelle planétaire à un certain moment de l'histoire universelle. En effet, la colonie est, sous bien des rapports, incontestablement un univers kafkaïen que la floraison du lexique cabralien décline fidèlement: barbarie, domination, exactions, prédations, pillages, esclavage, emprisonnement, assassinats, massacres, exploitation, humiliations, tortures, terreur, génocides, travail forcé, crimes, campagne psychosociale, division des peuples, morcellement territorial, etc. Elle est un espace de formatage d'êtres humains sans droits ni titres, sans dignité et sans la moindre valeur aux yeux de qui le regarde. Pour Cabral, des peuples "se trouvent soumis à la plus violente exploitation de l'homme par l'homme, sont objet de la plus monstrueuse oppression nationale, sociale et culturelle, et victime d'une barbare répression militaire et policière" (Cabral 1961). Ce fut l'asservissement de millions de "personnes", leur réduction effective à la bestialité par des marchands, des militaires, des missionnaires avec l'onction d'anthropologues, de scientifiques, de philosophes. En somme, une industrie et ses contremaîtres se sont constitués pour apporter la preuve que ces "êtres" sont d'une extraction ontologique différente, des "êtres" sans histoire ni culture, sans aucune contribution au progrès de l'humanité. "Les droits fondamentaux de l'homme, les libertés essentielles, le respect envers la dignité humaine - tout cela est inconnu dans nos pays..." (Cabral 1975b : 125-126). En effet, la société coloniale est une société de mépris cherchant à se fonder sur l'idée que cette "juste" domination ne vise qu'à émanciper des peuples-enfants, des individus faibles, sans conscience et congénitalement frappés d'une incapacité de se prendre en charge : "Des temps des " découvertes " ou 'achamentos', à la traite et aux crimes de l'esclavage; des guerres de conquête coloniale à l'âge d'or du colonialisme; des premières "réformes" outre-mer aux guerres coloniales de génocide de nos jours, les colonialistes [...] ont toujours fait preuve d'une mentalité superstitieuse et d'un racisme primitif à l'égard de l'homme africain, qu'ils considéraient et considèrent comme étant naturellement inférieur, incapable d'organiser sa vie et de défendre ses intérêts, facile à tromper, sans culture et manquant de civilisation" (Ibid.: 126). Ce constat, Cabral l'a déjà trouvé chez Aimé Césaire qui, dans son Discours sur le colonialisme, a brossé un tableau réaliste de l'entreprise coloniale, consistant à vider des sociétés, à écraser des cultures, à miner 
des institutions, à déposséder des groupes de leurs terres, à "assassiner" des religions, à anéantir des magnificences artistiques et à supprimer d'extraordinaires possibilités (Césaire 2000). Loin du style pamphlétaire du texte du poète antillais, Amílcar Cabral ne manque pas aussi de dénoncer les horreurs inhérentes au colonialisme en indiquant que "toute situation coloniale est une situation de domination par la violence... L'injustice, le manque de respect envers l'homme africain, le racisme, l'absence des libertés politiques, la misère, l'ignorance, la faim et la peur, l'oppression et la répression ont dépassé les limites" (Cabral 1975b : 126). Le colonialisme implique une oppression autolégitimante en produisant des discours et des techniques servant à rendre l'opprimé davantage semblable à ce qu'il faudrait qu'il fût pour mériter son sort. Convaincus de leur supériorité, les colonisateurs mettent tout en œuvre pour la consolider en refusant toute intégration et toute autonomie politique aux populations locales. Face à ce refus et à ces méthodes, les colonisés ne pouvaient que déduire "qu'on les excluait et qu'on les séparait à tout jamais du reste de l'humanité". Ces exactions constituent le substrat de la révolte de Cabral. Pour lui, la répression fondée sur la conviction des dominateurs en leur supériorité naturelle va se révéler contreproductive: "cela leur coûte cher, et leur coûtera de plus en plus cher, d'apprendre que nous sommes des hommes" (Ibid.).

En faisant planer de façon constante une violence polymorphe, le dominateur se sert de moyens symboliques pour ancrer davantage l'aliénation pérennisant le racisme et la soumission. Selon Étienne Balibar et Immanuel Wallerstein, dans le racisme colonial, l'autre n'est pas extérieur mais intérieur, même et surtout si cette 'intériorité' prend la forme de la répulsion ou de l'expulsion (Balibar \& Wallerstein 1997 : 125). Ce que Frantz Fanon a bien formulé en ces termes: "Ce n'est pas le sol qui est occupé. [...] Le colonialisme [...] s'est installé au centre même de l'individu et y a entrepris un travail soutenu de ratissage, d'expulsion de soi-même, de mutilation rationnellement poursuivie [...]. C'est le pays global, son histoire, sa pulsation quotidienne qui sont contestés [...]. Dans ces conditions, la respiration de l'individu est une respiration observée, occupée" (Fanon 1975: 300)³. Le fouet, le mépris, la négation, la force de persuasion transforment le sujet colonial en une nullité permanente dont la conséquence est qu'il finit par se convaincre qu'il est nul, incapable, méprisable, sans passé, sans avenir, éternellement à la merci de son maitre. Il développe un mépris et une haine de soi. Pour Cabral, le colonialisme consiste en un usage particulier du racisme. En effet, le colonialisme, en son essence et dans son incarnation, suppose un racisme directement lié au pillage des richesses des territoires conquis, à l'expansion du capitalisme qui se traduit par une domination politique se consolidant par la mise en place d'une administration et d'un arsenal juridique répressif dont la finalité en dernière instance est la gestion de l'exclusion et la perpétuation de cette domination. "Une nouvelle espèce socio-politique créée pour les besoins de la domination": "Aussi bien dans la vie publique que dans sa vie privée; dans son droit à l'enseignement que dans son droit à disposer de sa personne; dans le choix de ses dirigeants (même ceux qui exercent le moins de fonctions) que dans son activité politique; aussi bien qu'en liberté qu'en prison; dans ses rapports de famille que dans son travail ; dans son droit à la propriété que dans son droit à disposer du fruit de sa production - l'indigène ne jouit pas des droits communs aux hommes et est obligé de 'jouir' d'un statut spécial" (Cabral 1975a : 119). 
7 L'usage de la science comme arme idéologique fut constant et sans appel (Leclerc 1972). À cet égard, l'anthropologie a été un outil efficace, une "science coloniale" dont l'objet d'étude singulier, le sujet dominé, fut avant tout une "curiosité" inscrite aux frontières de l'humain. En effet, la colonisation, en discours et en pratique, fut fondée sur la supposition, la production ou la démonstration d'une inégalité raciale en vue d'autoriser l'appropriation d'êtres humains, de terres et de biens. Une bonne part de l'effort théorique et politique de résistance a consisté à déconstruire le discours de domination, à "détruire les vestiges virulents de l'idéologie esclavagiste et colonialiste", à ruiner la thèse de l'“immaturité pour l'autodétermination". En effet, l'objectif du colonialisme est analogue à celui du système totalitaire décrit par Hannah Arendt. Le but de ce dernier n'est pas tant l'extermination physique des hommes que l'instauration des conditions d'existence telles qu'être ou ne pas être ne fasse rigoureusement plus aucune différence, son coût humain se lit en termes d'absence de qualité de la vie, de négation de l'altérité et même d'existence: les dominés doivent être maintenus dans un espace entre la vie et la mort où tout se passe comme s'ils n'existaient pas. Le colonialisme se présente comme une forme pernicieuse de totalitarisme qui détruit les structures sociales constituant une barrière pour l'individu contre son écrasement par le système. Ce monde transforme l'être humain" en un individu conditionné exclu de l'humanité et du coup du politique. Il comporte en son essence un potentiel "humanicide" lui permettant de tirer de son propre logos la confirmation de l'existence des "races" (Arendt 1972).

8 La quasi-similitude du colonialisme avec le système totalitaire ainsi décrit ne fait pas l'ombre d'un doute. En effet, au début de toute entreprise coloniale, on retrouve non pas la découverte de nouvelles races, mais la fondation d'un nouvel espace commun où le racisme prend forme et se perpétue grâce à un régime d'oppression sans bornes morales: "Une fois isolé le trait de mœurs, fait historique ou géographique, qui caractérise le colonisé et l'oppose au colonisateur, il faut empêcher que le fossé ne puisse être comblé. Le colonialiste sortira le fait de l'histoire, du temps et donc d'une évolution possible. Le fait sociologique est baptisé biologique ou mieux métaphysique. Il est déclaré appartenir à l'essence du colonisé. Du coup, la relation coloniale entre le colonisé et le colonisateur, fondée sur la manière d'être, essentielle, des deux protagonistes, devient une catégorie définitive. Elle est ce qu'elle est parce qu'ils sont ce qu'ils sont, et ni l'un ni l'autre ne changeront jamais" (Memmi 1985: 90-91). Le colonisé finit par se percevoir comme étant "fatalement" un être de carence dont la dimension la plus grave est celle d'être placé hors de l'histoire et hors de la cité. La colonisation supprime en lui toute décision qui contribue au destin du monde et du sien, toute responsabilité historique et sociale. L'exclusion qui le touche entraîne inévitablement des situations où il est victime d'abus contre lesquels il n'a aucun recours.

\section{Violence et culture}

\subsection{De la violence révolutionnaire comme instrument de libération}

Dans Humanisme et Terreur, Maurice Merleau-Ponty discute du sens ou de l'avenir de la violence et cherche un usage d'elle qui se projette vers un avenir humain tendant à mettre fin à la violence (Merleau-Ponty 1948). Cela est perceptible dans certains textes 
de Cabral. Il ne s'agit plus de choisir entre violence et non-violence, mais entre différentes sortes de violence, de les subir ou de s'opposer à elles. En vérité, l'idée que la violence soit un choix par défaut transparaît de façon constante dans sa démarche politique, il s'en sert à son corps défendant. Dès le départ, il y a chez lui une ambivalence constitutive de la notion : rébellion et révolution à la fois, déconstruction de l'ordre colonial et démantèlement des traditions anachroniques, mais aussi construction, simultanément à l'engagement militaire, d'un nouvel ordre économique, culturel et symbolique. La proclamation de l'action directe par le PAIGC, le 3 août 1961 (Silva 2006), s'auto-légitime à partir de cette dualité qui signe le passage obligé de la lutte politique à celle de l'insurrection nationale.

Ce recours à la violence procède donc d'un réflexe d'autodéfense : "au regard de notre peuple conviennent tous les chemins, procédés ou modalités qui lui rendent son droit inaliénable à l'autodétermination et le conduisent de façon irréversible à la liquidation immédiate de la domination coloniale..." (Cabral 1975b:251). Cette fin justifie les moyens. Des limites morales existent pourtant. En effet, la conception cabralienne de la guerre, et de la violence en général, se situe aux antipodes de celle de Carl von Clausewitz. La thèse centrale de ce dernier s'articule autour de l'idée que la guerre est un acte de violence dont l'usage ne connaît a priori aucune limite, d'où la présupposition de la normalité des extrêmes (Clausewitz 1959). Cabral était fort éloignée de cette conception. Pour lui, la guerre n'a pas été, n'est pas d'abord et en son essence un "acte de violence" qui tendrait vers la violence absolue. Elle est, en son fond et en sa substance même, un acte de culture ${ }^{4}$. Cette conception pourrait tenir de L'Art de la Guerre de Sun Tzu dont la stratégie consistait à neutraliser l'ennemi en lui faisant comprendre qu'il valait mieux ne pas faire la guerre (Tzu 2015). La guerre de Cabral est une guerre malgré soi, une guerre contre la guerre! C'est pourquoi elle ne fut jamais une guerre de militaires mais de «militants armés». Sa guerre préparait dans son processus même, et à tous les niveaux, la paix en humanisant celui qui la faisait, en lui faisant comprendre la dimension humaine de l'ennemi et en le projetant dans la société future dont les fondations devaient être édifiées par tous.

L'appel aux ressorts anthropologiques de chacun, y compris l'ennemi, reposait sur la conscience qu'à un moment de l'histoire le recours à la violence peut être une voie obligée, mais la fin ultime reste la mise en place des conditions assurant le bonheur de l'homme, d'où l'idée que cette lutte est de nature foncièrement politique. En conséquence, sa théorie et sa pratique de la guerre sont incontestablement les contremodèles même de celles évoquées précédemment. Comment dès lors faire la paix en temps de guerre? "Naturellement, nous n'aimons pas que le peuple sente la guerre; mais nous souhaitons beaucoup résoudre les contradictions pour en finir avec cette guerre" (Cabral 1975b: 235). Pour cela il s'est agi de développer et d'intensifier la guerre pour l'abréger. Abréger la guerre revient, "à chaque moment et dans toutes les activités - y compris la guerre - à consolider et renforcer "les structures du Parti et de la lutte, faire que chaque organisme joue réellement le rôle qui est le sien, que chaque militant se sente chaque jour plus responsable et nécessaire au progrès de la lutte; développer davantage la démocratie, l'esprit de critique et d'autocritique, de la base au sommet de notre organisation ; accomplir et faire accomplir les mots d'ordre et toutes les directives du Parti ; améliorer le rendement du travail de chaque organisme et de chaque militant ; renforcer le combat contre la fainéantise, la facilité, l'opportunisme et toutes les déviations morales ou politiques de la ligne tracée par le Parti; déblayer 
progressivement les obstacles à la réalisation de ce but majeur de notre lutte : que notre peuple prenne totalement dans ses mains le pouvoir politique que notre combat a déjà conquis sur les deux tiers de notre territoire national. Voilà qui constitue des tâches fondamentales de la lutte, nous permettant de garantir et de transformer postérieurement les perspectives favorables de notre combat libérateur" (Ibid.: 132). D'où l'attention portée à l'élaboration d'une idéologie et à une construction des alliances fondée sur l'unité et la solidarité, à l'échelle universelle, entre travailleurs, paysans, chômeurs et classes moyennes. Une telle unité ne peut être spontanée, elle s'édifie patiemment, prudemment. "Notre lutte armée n'est qu'un aspect de la lutte générale des peuples opprimés contre l'impérialisme, de la lutte de l'homme pour sa dignité, pour la liberté et pour le progrès. C'est dans ce cadre que nous devons être capables d'intégrer notre lutte. Nous devons nous considérer comme des soldats, maintes fois anonymes, mais des soldats de l'humanité dans ce vaste front de lutte qu'est l'Afrique de nos jours ... Nous nous battons en Afrique parce que l'Afrique est notre patrie, mais nous serions prêts nous tous à aller n'importe où pour nous battre pour la dignité de l'homme, pour le progrès de l'homme, pour le bonheur de l'homme" (Ibid.: pp. 226-7). La guerre introduit une nouvelle éthique qui va au-delà du droit et qui vise la sauvegarde de l'humain par l'éradication de la violence oppressive. Le postulat ici est que cette lutte ne doit pas être laissée entre des mains de gens assoiffés de sang, mais elle doit être menée par des gens lucides et honnêtes, les "meilleurs fils" $\mathrm{du}$ pays. Cette théorie du gouvernement des meilleurs ne se fonde pas sur une aristocratie ou une technocratie ségrégative, mais sur l'immersion des cadres dans la population. Il y a un dépassement de la filiation aristotélicienne par un réalisme politique se nourrissant d'une axiologie profondément ancrée dans l'humain.

Que vaut alors une éthique qui recourt à la violence ? La fin justifie-t-elle les moyens? On ne peut esquiver le dilemme moral et, surtout, l'angoisse vécus par chaque combattant conscient de la barbarie inhérente au recours à la force, de son inéluctabilité mais surtout, dans le cadre des principes éthiques de la lutte armée de libération, de l'existence d'un seuil infranchissable dans l'usage de la violence au-delà duquel on verse dans l'abus. La lutte de libération, comme guerre et comme construction révolutionnaire, installe chez chaque combattant une contrainte assumée qui se transmue en éthique de guerre sous la forme d'une tension morale qui endigue, dans des limites étriquées, le recours à la force.

La lutte armée de libération nationale est différente du terrorisme, d'une action sans aucune borne morale. En effet, il y a un noyau rationnel dans la lutte de libération interdisant au combattant de se conduire en bourreau, la lutte ne cherche pas à instaurer la terreur. À ce niveau apparaissent des aspects importants liant les positions de Cabral à celles de Hannah Arendt. Celle-ci établit une distinction entre violence et terreur laquelle apparait comme une forme de politique survenant lorsque la violence, ayant détruit toute forme de pouvoir, se transmue en une sorte de contrôle total. Sa théorie inclut un scénario où l'effectivité de la terreur dépend du degré d'autonomisation sociale. La différence entre gouvernement totalitaires, tyrannies et dictatures réside dans la différence entre violence et terreur. Le climat de terreur est atteint quand le pouvoir est complétement détruit et le système de politique autophagique. Comme Arendt, Cabral soutient l'existence d'une forme spécifique de terreur dans un contexte colonial assimilable à celle qui règne dans les régimes totalitaires. Au total, la lutte armée de libération nationale constitue le seul moyen s'offrant au peuple de recouvrer un droit inaliénable consacré par la légalité 
internationale. Ce droit possède un fondement moral irréfutable à savoir l'aspiration légitime à la dignité, à la justice, à la liberté et au progrès (Arendt 1972:103, Cabral 1975a, Cabral 1975b).

\subsection{De la culture comme arme : le discours et la méthode}

14 Par culture, il faut entendre un complexe de faits sociaux et psychologiques instables présentant un caractère religieux, moral, esthétique, technique ou scientifique. "La culture est la synthèse dynamique au niveau de la conscience de l'individu ou de la collectivité de la réalité historique, matérielle et spirituelle de la société ou d'un groupe humain, des relations prévalant aussi bien entre l'homme et la nature qu'entre les hommes et les catégories sociales" (Cabral 1975a: 351). La culture a une fonction d'unification, elle résulte du rapport des hommes avec la nature et entre eux. Elle relève des pratiques sociales, des manières d'être des individus d'une société, elle réside au niveau de la conscience individuelle et collective. Cabral s'inscrit d'emblée ici comme protagoniste d'un débat décisif, sérieux, aussi vieux que la science anthropologique elle-même: quel est le fondement de l'identité, la biologie ou l'histoire? En effet, les théories anthropologiques racialistes qui nourrissent ce débat tout au long des $\mathrm{XVIII}^{\mathrm{e}}$ et $\mathrm{XIX}^{\mathrm{e}}$ siècles préparent le socle idéologique de légitimation de pratiques racistes inhérentes à l'esclavage et à la colonisation.

Cabral s'est fait anthropologue au début de son action politique en réfutant le biologisme et en montrant la prépondérance du facteur culturel dans la définition de l'homme. C'est dans la conception de la culture que se situe l'une des originalités majeures de la pensée de Cabral. Selon Roland Colin, la culture est comprise ici non comme une essence atemporelle mais comme "une réalité vivante, permettant aux acteurs de l'histoire d'assumer pleinement leur modernité et leur créativité, donc de concourir, sans s'y diluer, à l'universel où la marque de chacun préserve son visage ainsi que la mémoire de ses racines" (Colin 2012 : 104). La culture n'est pas séparée des réalités économiques et sociales, elle est consubstantielle à tout être dont la nature consiste à devenir. Cabral pourrait faire siennes les positions de Rousseau et de Fichte qui considèrent l'homme comme un être dont la nature se caractérise précisément par un manque d'être, il est ce qu'il est appelé à être: un être de culture. Cette qualité particulière serait, selon Rousseau, une sorte de ruse de la raison qui œuvrerait à le distinguer de l'animal, d'où sa faculté à se perfectionner ${ }^{5}$. En effet, l'humanité de l'homme résiderait dans la possibilité de devenir quelque chose de non naturel et de produire des objets non directement issus de la nature. La différence entre les hommes se situerait exclusivement dans les modalités résultant des facteurs exogènes et non de qualités intrinsèques, génétiques. Cette dimension est d'autant plus actuelle que c'est à notre époque que Samuel Huntington a théorisé le "choc des civilisations", laissant comprendre que notre présent et notre avenir sont régis sous le sceau de l'identité, de l'affrontement entre les races, les religions, les systèmes politiques. Il en fait un des enjeux de civilisation de notre temps (Huntington 2000). Les thèses de Cabral apparaissent alors comme une réponse anticipée à la résurgence des théories raciales et racistes classiques, et comme propédeutique à l'édification de la société nouvelle. La critique de la culture s'effectue à trois niveaux :

- Celui de l'analyse de la répression exercée par l'ordre colonial sur les aspects de la culture comme niches de résistance et d'anachronisme, notamment la psychologie de la petite 
bourgeoise confrontée à un problème de dépassement de l'aliénation et de représentation de soi.

- Celui de l'action de sensibilisation politique sur le front de lutte ou lors de la construction de la nouvelle société, précisément la confrontation avec les survivances culturelles rétrogrades, obstacles à la rationalisation et au développement de la lutte et, surtout, frein au développement économique et social.

- Celui de la compréhension du processus de libération comme dynamique de création culturelle, comme processus d'émergence d'un nouveau sujet apte à saisir les réalités historiques contemporaines. Sous ce rapport, la lutte armée apparait comme un facteur d'influence sur les consciences, donc comme facteur de culture générateur d'une personnalité nouvelle.

16 Cette triple visée alimente toute la démarche ultérieure de mobilisation et d'éducation politiques. Le travail sociologique et agronomique effectué durant cette période constitue la première étape servant de point d'impulsion à la lutte armée. Il a pu saisir à cette occasion la réalité sociale et culturelle comme recelant des possibilités de transformation infinie. En effet, la démarche de "l'ingénieur des consciences" fut une entreprise de connaissance et de construction d'un homme nouveau. C'est dire que la résistance s'est jouée d'abord sur le mode pacifique de la clandestinité avant d'emprunter ouvertement les sentiers sinueux de la guerre. La colonisation a établi et maintenu son pouvoir en tentant d'éradiquer les cultures du sujet colonial. Comme le note justement Firoze Manji, la culture n'est pas un simple artéfact esthétique mais une expression de l'histoire des sociétés qui se transforme. Elle a été fondamentale pour les colonisés dans la réaffirmation de leur identité, pour réinventer ce que signifie être humain et par la suite, développer une certaine humanité (Manji 2017).

17 La culture a été de tout temps un ferment de résistance clandestine ou ouverte, une force de libération avant d'être elle-même fécondée par la lutte. Le problème de la culture s'analyse avant tout chez Cabral en fonction du paradigme général que constitue la lutte de libération. C'est au regard de l'engagement pour la libération nationale que la culture est appréhendée. Très tôt il a perçu la dimension essentielle de la culture dans l'action politique, à la fois dans ses aspects positifs et négatifs, comme phénomène historique résultant du vécu social. Pour lui, il y a à essorer les faits culturels afin d'en éliminer certains et d'en retenir ceux qui épousent la trajectoire ascendante de l'Histoire. "Notre lutte est fondée sur notre culture, parce que la culture est le fruit de l'histoire et qu'elle est une force. Mais notre culture est pleine de faiblesses devant la nature. Il faut le savoir" (Cabral 1975a : 200). Le fait culturel tient une place particulière dans le processus de transformation politique. L'analyse de l'écosystème de la lutte intègre une certaine relativité, celle de la prise en compte des lieux et des moments de l'action politique et militaire. Pour cela, un préalable est nécessaire: celui de la profonde connaissance des réalités concrètes et des comportements des populations. Par ce biais, il a fait pénétrer les nouvelles idées politiques au cœur des hameaux tout en extirpant tous les éléments rétrogrades qui freinent la lutte et obstruent l'orifice d'émergence de la société nouvelle. D'où la définition d'une pédagogie politique pouvant déclencher l'adhésion des populations à la lutte armée. Le caractère historique de la démarche se situait dans la signification que Cabral se donnait comme tâche prioritaire : former des hommes. Et la lutte armée de libération devient à son corps défendant une ressource pédagogique génératrice malgré tout et de fait de nouveaux hommes et même de l'homme total. 


\section{L'œcuménisme de l'éthique de résistance} plaçant l'être humain au-dessus de toute autre contingence comme fin en soi. C'est fort de cela qu'il a le courage de "proclamer à haute voix [ses] options fondamentales, [ses] options en faveur de l'humanité" (Cabral 1975b : 227). On voit par-là que le souci de l'homme apparaît comme une préoccupation importante, un souci éthique omniprésent voisinant organiquement avec le souci de l'autre, du progrès, de la paix, de la dénonciation de la course aux armements, la haine de la guerre, au service de la liberté, de la fraternité et du bonheur des hommes (Ibid.: 247). La lutte armée de libération nationale, en convoyant avec elle le progrès, apparait comme un processus caractéristique d'une révolution: toute lutte contre l'oppression est donc dans une large mesure un effort de conscientisation des opprimés pour se prémunir de la haine revancharde et pour construire une société nouvelle.

\subsection{Pour une fraternité universelle}

Une fraternité d'armes habite les combattants impliqués dans la lutte de libération ${ }^{6}$, d'où le rôle crucial de la résistance culturelle dans le processus de libération nationale : la culture comme refuge et comme procès de création continuée de valeurs. Elle exprime l'humain et se retrouve au centre de l'action politique. Chaque combattant devrait avoir un respect immédiat, un pur respect qui suffit à faire céder tout autre motif fondé sur l'inclination : le devoir de tout militant épouse la raison commune des hommes. Ainsi, malgré les tournures dramatiques auxquelles les peuples africains ont eu à faire face et que Cabral a vécu, il prévaut chez lui et les siens une croyance en la fraternité humaine et en l'existence d'un esprit de compréhension universelle. D'où cet appel œcuménique, en dépit de la "gravité de l'heure", qui s'adresse à "chaque homme et chaque femme" sommés d'assumer leurs responsabilités historiques articulées autour des aspirations au progrès et à la pleine jouissance des droits pour tout sujet humain envers qui il faut être solidaire partout où il se situera. "Nous nous considérons comme faisant partie d'un vaste front de lutte pour le bien de l'humanité" (Ibid.: 229).

Le combat de Cabral ne s'inscrit pas dans une optique revancharde: "Nos peuples ne luttent pas pour se venger de ceux qui ont commis dans la pratique les crimes du colonialisme ... ils luttent pour reconquérir leur liberté et leur dignité - éléments fondamentaux de leur condition humaine" (Ibid.: 18)7 ${ }^{7}$. La claire conscience de leur humanité conduit, naturellement, à l'acceptation de la résistance comme réflexe naturel pour tous les humains comme celle d'agents historiques aspirant à la maitrise de leur existence. Le propre de l'homme, de tout homme consiste à vouloir maîtriser le cours de sa vie, de s'inventer un avenir par la production et la création d'institutions et d'objets propres à lui révéler son identité, sa valeur et à améliorer ses conditions de vie. Cette propension démiurgique est un fait humain universel: "tout être humain, de toute origine" travaille à "développer librement sa personnalité et de contribuer de façon efficace au progrès de tous" (Ibid.: 17). C'est dans la liberté et non dans l'oppression que les potentialités de chaque peuple éclosent car "l'oppression n'est pas et ne sera jamais une école de vertus et d'aptitudes pour aucun peuple" (Ibid. : p. 61). La lutte se mène dans le cadre d'une défense sans concession de principes humanistes de 
liberté, de justice, d'indépendance véritable, de renforcement de l'action politique et du travail de reconstruction nationale, d'amélioration de la conscience politique des populations ainsi que celle du comportement individuel des militants. Il s'agit de mener de pair la lutte armée de libération et de construction des individus, d'édification de la nation et de la société nouvelle. La génération de nouvelles consciences et de nouveaux instruments juridiques sort de l'informel normatif et de la justice expéditive, corollaires de l'arbitraire du militarisme.

\subsection{Droit à l'existence et initiative historique}

21 À toutes les étapes de la lutte et de l'effort de compréhension des phénomènes politiques, culturels, sociaux et militaires, se trouve la claire conscience de la légitimité de la lutte et, surtout, de l'inéluctabilité de la marche de l'histoire orientée vers une reprise de l'initiative par chaque peuple. L'ancrage dans une légitimité anthropologique sert de point d'impulsion à la projection historique. La saisie de la marche des choses est quasi téléonomique, car il s'agit de répondre à une sorte de projet œcuménique de recherche de l'humain chez tout homme. Cette attitude rend compte d'une conception de l'unité du genre humain, de la commune aspiration à la paix, à la liberté, à l'égalité et à la jouissance intégrale des droits attachés à chaque peuple et à chaque individu.

22 À cet égard la reprise synchrone de l'initiative historique par des peuples très différents et en divers endroits constitue un retour à une normalité historique qui traduit le destin solidaire des uns et des autres : "D'éléments passifs, conditionnés par une domination particulièrement rétrograde et par les contingences politiques des peuples voisins, nous sommes devenus un facteur actif du processus historique en cours dans le continent. Notre destin - celui de nos peuples - s'est ainsi lié d'une manière explicite et irréversible au destin de l'Afrique qui se forge chaque jour dans la lutte commune contre la domination étrangère" (Ibid.: 31). La douleur du travail de mémoire est atténuée par le sentiment de dignité retrouvée, de la volonté d'instauration de la justice pour tous, sans ségrégation, sans exploitation. Cabral traduit ce sentiment d'être redevenu pleinement humain en étant le pilote de sa propre histoire : "Nous marchons dans le sens de l'Histoire et avons à nos côtés, de plus en plus décidées à nous aider, toutes les forces progressistes du monde" (Ibid. : 162). C'est une lutte pour l'homme, pour l'existence et pour le droit de tous à l'existence, à une coexistence pacifique : "pour coexister, il faut d'abord exister" (Ibid. : 249). Cette lutte armée est une lutte, aussi paradoxal que cela puisse être, pour la coexistence pacifique et pour la paix. Il transparaît ici une mystique de la paix et du progrès auxquels chaque groupe humain et chaque individu ont droit. C'est un juste retour au banquet universel.

\section{Conclusion}

La double conscience, celle du déni de justice inhérent à la domination coloniale, et celle de la nécessité de lutter pour exister et mieux exister, demeure le socle de cette pensée renvoyant à l'idée hégélienne de la conscience malheureuse qui finit par se dépasser et aboutir à une synthèse réconciliatrice. La démarche est faite de part en part de la positivité dans la méthode, dans les moyens investis dans la lutte, dans la considération du sujet humain, dans l'aspiration à la paix et au progrès. Chacune de ces dimensions appelle un dépassement de soi. Ainsi, avec l'avantage du recul critique, 
nous pouvons deviner aisément l'écart psychologique quotidien auquel Cabral était soumis. L'examen attentif des situations renseigne amplement sur une plasticité intellectuelle qui, fondée sur l'écoute et l'analyse, exige un douloureux effort, une tension psychologique permanente ne se dérobant pas au dialogue, au débat sans concession qui vise à combattre toutes les idées et les pratiques pernicieuses, tout en restant sur une position éthique œcuménique fondée sur une certaine idée de l'homme comme idée régulatrice. Au total, la tension découle de cette audace consistant à oser penser contre les hégémonismes (les traditions et l'impérialisme) et à user de moyens violents en dépit souci éthique constant. Le fait d'accorder de l'importance aux faits de culture et à la lutte comme facteur de culture n'est pas une ruse politique, mais rend compte d'un projet de cité nouvelle conscient de la diversité culturelle de son matériau, des différences de situations et de la nécessité de construire un homme nouveau dans un cadre national profondément hétérogène. La permanence de la préoccupation éthique s'accommode douloureusement de réalisme politique.

\section{BIBLIOGRAPHIE}

Andrade, M. de 1980, Amilcar Cabral. Essai de biographie politique, Paris, François Maspero.

Arendt, H. 1972, Du mensonge à la violence, Paris, Calmann-Lévy.

Balibar, E. \& Wallerstein, I. 1997, Race, nation, classe. Les identités ambiguës, Paris, La Découverte, coll. Poche.

Cabral, A. 1975a, Unité et lutte I, l'arme de la théorie, Paris, Maspero.

Cabral, A. 1975b, Unité et lutte II, La pratique révolutionnaire, Paris, Maspero.

Césaire, A. 2000, Discours sur le colonialisme, Paris, Présence Africaine.

Clausewitz, C. v. 1959, De la guerre, Paris, Éditions de Minuit.

Colin, R. 2012, “ La pensée et la pratique sociale et politique d'Amilcar Cabral sur les chemins de l'histoire”, Présence Africaine, 185-186 (1-2) : 95-105.

Fanon, F. 1975, L'An V de la révolution algérienne, Paris, Maspero.

Huntington, S. P. 2000, Le Choc des civilisations, Paris, Odile Jacob.

Leclerc, G. 1972, Anthropologie et colonialisme, Paris, La Découverte.

Lévi-Strauss, C. 1983, Le regard éloigné, Paris, Plon.

Manji, F. 2017, Culture, power and resistance: reflections on the ideas of Amilcar Cabral, The Transnational Institute (TNI), consulté le 22 Décembre 2019, www.tni.org/stateofpower2017.

Memmi, A. 1985, Portrait du colonisé suivi du portrait du colonisateur, Paris, Gallimard.

Merleau-Ponty, M. 1948, Humanisme et terreur. Essai sur le problème communiste, Paris, Gallimard/ Idées.

Nkrumah, K. 1964, Le Consciencisme, Paris, Payot. 
Rabaka, R. 2009, Africana Critical Theory: Reconstructing the Black Radical Tradition, from W. E. B. Du Bois and C. L. R. James to Frantz Fanon and Amílcar Cabral, New York, Lexington Books.

Silva, A. E. D. 2006, “Guiné-Bissau : a Causa do Nacionalismo e a Fundação do PAIGC”, Cadernos de Estudos Africanos, 9-10:142-167.

Tzu, S. 2015, L'art de la guerre, Paris, Fayard/Pluriel.

\section{NOTES}

1. À ce sujet, le texte publié dans la revue Agros, Volume XLII (4), 1959, constitue une radiographie nette de tous les compartiments de la vie socio-économique de la Guinée "portugaise". Même si le but initial de cet article était de "présenter quelques notes sur les caractéristiques et les problèmes fondamentaux de l'agriculture en Guinée", il n'en reste pas moins qu'il dresse un tableau exhaustif de la diversité des peuples qui y vivent et de la complexité de leurs relations: "Cette variété des peuples est une des caractéristiques de la Guinée. Diverses populations négro-africaines y vivent côte à côte, dont les origines posent encore aujourd'hui un problème à l'ethno-histoire. Sur une base commune de culture et de civilisation africaines, la diversité est flagrante dans tous les domaines : depuis la couleur de la peau jusqu'à la forme d'habitation et de peuplement; de la langue à la religion; de l'habillement au régime alimentaire; de l'instrument agricole jusqu'aux règles de mariage; de la division du travail jusqu'à la répartition des richesses. Dominant cette diversité dans laquelle les interinfluences sont fréquentes, ces peuples subissent l'emprise de la situation politico-sociale commune et vivent sur une base de vie identique : l'agriculture" (Cabral 1975a : 57).

2. Kwamé Nkrumah (1909-1972), homme politique du Ghana et leader panafricaniste ayant conduit son pays à l'indépendance en 1957, a élaboré un système philosophique appelé " consciencisme» qui se présente comme une théorie matérialiste dont la dialectique est le moteur. Son souci fut de chercher à construire une théorie et une méthode de la libération qui visent une décolonisation totale et une libération culturelle effective. Sa théorie n'est pas seulement un ensemble de recettes pragmatiques mais elle est surtout une "philosophie et idéologie ». La thèse principale de cette approche consiste à soutenir que la philosophie surgit toujours d'un milieu social conflictuel et que, sous son aspect social, elle met en avant une idéologie qui prend en charge cette dimension conflictuelle. Le consciencisme apparaît comme instrument d'intégration d'une nation en construction puisqu'elle dégage des valeurs communes pour la nation. Nkrumah montre que l'idéologie est toujours le reflet d'une philosophie, c'est pourquoi il entreprend d'élaborer une philosophie adaptée à l'Afrique et porteuse d'une dialectique permettant de dépasser les conflits.

3. Pour une plus ample comparaison entre Frantz Fanon et Amílcar Cabral voir Rabaka, R. 2009, Africana Critical Theory: Reconstructing the Black Radical Tradition, from W. E. B. Du Bois and C. L. R. James to Frantz Fanon and Amilcar Cabral, New York, Lexington Books ; Peterson, C. F. 2007, DuBois, Fanon, Cabral : The Margins of Elite Anti-Colonial Leadership, Plymouth, Lexington Books.

4. La théorie de la culture se distribue dans la plupart des écrits politiques de Cabral. La culture a été un terreau polymorphe de résistance sourde ou cachée à la domination. Une résistance pacifique à la violence coloniale, et avant elle, à la traite et à l'esclavage ou aux travaux forcés. Cette dimension de la culture comme capital de résistance est importante à souligner du fait de sa triple modalité : d'abord comme fait anthropologique incarnant une identité, ensuite comme point d'impulsion et comme refuge, lieu de repli et de résistance et enfin comme facteur de création d'une personnalité nouvelle pouvant conduire à l'émergence d'une nationalité et à la transformation de populations hétérogènes en peuple se projetant vers un horizon historique commun. 
5. Voir notamment le Discours sur l'origine de l'inégalité parmi les hommes, précisément la Première partie où Rousseau indique que la qualité qui distingue les hommes, c'est la faculté de se perfectionner laquelle est au fondement de toutes les autres et qui ne se retrouve pas chez les animaux.

6. Selon Cabral, "chaque goutte de sang qui tombe chez nous tombe également du corps et du cœur de nos frères africains" (Cabral 1975b : 230).

7. C'est nous qui soulignons.

\section{RÉSUMÉS}

Comment concilier le recours à la violence avec l'invocation de valeurs ? Comment accorder la primauté à l'humain tout en adhérant à un réalisme politique ? Une démarche méthodique alliée à une certaine proactivité permet à Cabral de dépasser cette antinomie apparente entre les principes éthiques et l'usage de la violence. La guerre est ici un moyen de résistance à l'oppression et d'édification d'une société aspirant au progrès et à la liberté. Cette guerre est aux antipodes de l'apologie de la violence gratuite, elle se veut une "guerre à visage humain", celle "militants non de militaires". De cette tension entre morale et politique devra germer un nouvel homme ancré dans son topos culturel et dans des valeurs humanistes sans rapport avec l'univers colonial aliénant. Ainsi, la lutte de libération, constant dépassement de soi, se veut un processus de gestation anthropologique continu.

Como conciliar o uso da violência com a invocação de valores? Como dar primazia ao humano aderindo ao mesmo tempo a um realismo político ? Uma abordagem metódica combinada com uma certa pró-atividade permite a Cabral superar essa aparente antinomia entre os princípios éticos e o uso da violência. A guerra é aqui um meio de resistência à opressão e à construção de uma sociedade que aspira ao progresso e à liberdade. Esta guerra está nas antípodas da apologia da violência gratuita, ela se pretende como uma "guerra com rosto humano", a dos "militantes não militares". A partir dessa tensão entre moralidade e política, um novo homem enraizado no seu topos cultural e nos valores humanistas não relacionados ao universo colonial alienante terá que brotar. Assim, a luta pela libertação como uma constante superação de si mesmo é um processo de gestação antropológica contínua.

How to reconcile the recourse to violence with the invocation of values? How to give priority to human beings while adhering to political realism? A methodical approach allied to a certain proactivity allows Cabral to overcome the visible antinomy between the ethical principles and the use of violence. Here, war is a means of resistance against the oppression and also a way to construct a society yawning progress and liberty. This fight being the extreme opposite of the gratuitous violence apology, claims to be a "war to human face" meaning that it is "for militants but not for soldiers". From this tension between moral and politics, a new man should emerge who will be anchored in his cultural belief and in humanist values with no link to the alienating colonial universe. As an overtaking of oneself, the liberation fight claims, therefore, to be a ceaseless anthropological elaboration procedure. 
INDEX

Mots-clés : anthropologie, colonialisme, violence, politique, libération

Palavras-chave : antropologia, colonialismo, violência, política, libertação

Keywords : anthropology, colonialism, violence, politics, liberation

\section{AUTEUR}

MAMADOU KABIROU GANO

Département de Philosophie, Université Cheikh Anta Diop, Sénégal

kabirgano[at]yahoo.fr 